\title{
Exploring the Diversity of Everyday Experiences through the Humans of the University of Wisconsin-Stout
} Facebook Assignment

\author{
Genesea M. Carter
}

Colorado State University

Genesea M. Carter is the Associate Director of Composition and a Special Assistant Professor of Rhetoric and Composition at Colorado State University where she teaches rhetoric and composition and facilitates programmatic professional development. Her work has appeared in Composition Studies, The Journal of Teaching Writing, Open Words: Access and English Studies, and Teaching History: A Journal of Methods. She is currently co-editing Network Theories, Social Justice, and Supersystems in Writing Program Administration, which will, hopefully, be published in 2023. Maybe, one day, she'll write about being homeschooled, raised evangelical, and becoming a progressive academic. She lives in Fort Collins, Colorado, with her husband and two muted tortoiseshell cats, Alice and Florence.

I have learned a lot from this project. At first when you said that we would be doing this I thought it was pointless, but the more I did it the more I realized that you were helping us learn to talk to people. Communication is a huge skill in becoming successful. People who run businesses like people who can communicate well, and people who are good at speaking to others. Another thing I learned was people like to talk about the hard times they have had in their lives. To me, it seemed like they just like knowing that someone was actually listening to what they had to say.

—James, first-semester student, English 101

A

ccording to James, the Humans of the University of Wisconsin-Stout (HOUWS) Facebook assignment, an assignment I created and taught from 2015 to 2017 across my lower- and upper-division composition courses and based on Brandon Stanton's Humans of New York (HONY) storytelling and photography project, was to teach my students how to communicate and listen to people. And he's right-that was one of my goals. The HOUWS assignment (Appendix A) was the first assignment of the semester in my English 101 course, the first course in a two-course first-year composition (FYC) sequence, that I taught as a newly hired assistant professor at the University of Wisconsin-Stout (UW-Stout). In the assignment, students collect six stories and representative photographs of campus members, including students, visitors, faculty, and staff, and share them on the public HOUWS Facebook page. I created this assignment to encourage my students to listen to, to be curious about, and to experience what I call "the diversity of everyday experiences." I define the diversity of everyday experiences as the diversity people experience all day, every day, through ways of thought, ways of communicating, ways of living, ways

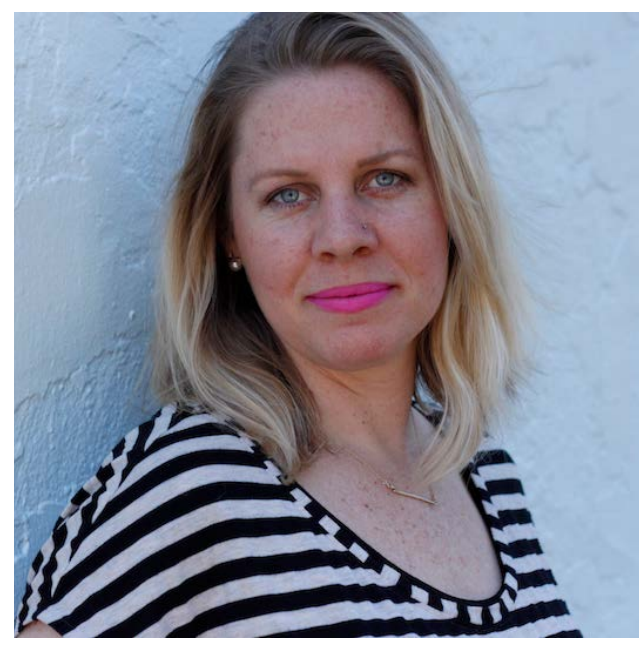

\begin{abstract}
In this personal essay and research article mash-up genre, I reflect on my Humans of the University of Wisconsin-Stout first-year composition Facebook assignment, which was developed to teach my predominately white students about the diversity of everyday experiences. I share with readers how my positionality, as a former evangelical Christian Republican who left Christianity and became a liberal progressive a few years before this assignment, and the context of my university, a predominately white, midwestern polytechnic university, shaped my assignment design. I include Humans of UW-Stout Facebook stories, corresponding student reflections and homework, and my own personal reflection on the curriculum to empower instructors to teach diversity-focused FYC assignments and to inspire instructors to reflect upon how their own political and religious beliefs shape their curriculum.
\end{abstract}

\section{Keywords}

First-year composition, diversity, positionality, Facebook, curriculum 
of experiencing intersectionality and positionality, ways of being in the world, among other diverse lived experiences (see Duyvendak, Foner, and Kasinitz; Rymes; Wise and Velayutham). Diversity of everyday experiences also includes race, ethnicity, and identity, as ways of living, ways of experiencing intersectionality and positionality, and ways of being in the world are different for marginalized people than for white, dominant, cisgender, heterosexual people.

The genre of this article is a mash-up of a personal essay and research article. ${ }^{1}$ I blend personal narrative, theory, student writing, and reflection to examine what I and my students learned from the HOUWS assignment and how my positionality shaped my curriculum and pedagogy. Having lived most of my life as an evangelical Christian Republican, I was keenly aware of the conversations that were not happening among white, conservative students in conservative cities and states. While at UW-Stout, I saw firsthand the conservatism on campus and in the small community of Menomonie, Wisconsin. My own experiences as a former white evangelical Christian Republican who did not learn about white privilege and structural racism until my early thirties compelled me to think critically and reflectively about my own (former) evangelicalism and Republicanism, while grappling with newfound progressive truths I felt I could no longer ignore. My ideological shifts paired with the predominately conservative culture of UW-Stout caused me to want to make significant changes in my FYC course design, particularly curriculum shifts around teaching about the importance of diversity, equity, inclusion, and identity. But I was really scared: I was scared I would fail, make a mess of it all, cause a revolt, and/or get terrible student evaluations in my new tenure-track job. Nevertheless, I could not shake these questions:

- How do I facilitate meaningful conversations about diversity, social justice, identity, intersectionality, positionality, and so forth, with my students?

- How do I talk and teach about the lived experiences of US citizens who are people of color in a meaningful way?

- How do I impress upon my students that diversity is good and necessary?

- How do I encourage my students to seek out diversity of thought, belief, experience, background, and so on?

- How do I use my own personal growth to inform my curriculum and pedagogy?

As you read this article, I hope you will consider one or more of these questions, perhaps with a journal by your side, to guide your own reflection about how your identities, positionalities, intersectionalities, and personal growth inform your teaching—or hold you back from making much-needed changes to your pedagogy and course design.

I designed the HOUWS assignment as a first attempt to answer the reflection questions above, and I share with readers the HOUWS stories, photographs, and student reflections of three students from one fall 2015 section of English $101,{ }^{2}$ the first course in a two-course sequence. These examples show students create content with very clear and meaningful rhetorical purposes in mind, namely building campus community and camaraderie, with an emphasis on belonging and not feeling alone. While most students were reticent to approach strangers on campus, at the end of the assignment all their reflections showed they were passionate about this assignment and felt it had changed their perspectives in some way. Students' reflections and process work indicate they want to work on their active listening skills and open-mindedness and stop making assumptions or judgments about people.

\section{FROM EVANGELICAL CHRISTIAN TO LIBERAL, DECONSTRUCTED CHRISTIAN}

My positionality is important to share because it informed and shaped my HOUWS assignment and course design. I am a white, cisgender, heterosexual woman who grew up in Paso Robles, California, an evangelical, Republican, white-dominant, California ranching and tourist town of thirty thousand residents. I was homeschooled kindergarten through high school by evangelical parents, and evangelicalism totally defined our identity and worldview. My parents raised my two siblings and me with the beliefs that God gave us an identity through $\mathrm{Him}$, which was the only identity that mattered, and that evangelical Christianity was the only correct and spiritually accurate worldview. ${ }^{3}$ Even though we talked about racism and the history of racism in the United States, we never talked about whiteness, white identity, or white privilege.

I remained an evangelical Christian Republican through the early years of my doctoral program at the University of New Mexico, a Hispanic-serving institution, even though the cracks in my religious and political beliefs began forming during my undergraduate education. Towards the end of my master's degree and at the beginning of my doctoral program, I began seriously questioning my evangelical beliefs and Republican ideology, largely due to my graduate coursework, research, and local discourse. Albuquerque, New Mexico, has robust National Public Radio affiliate stations, unlike the local programming in my part of California, which introduced me to extensive conversations and research about New Mexico's political, social, and economic stories that challenged my Republican-centric assumptions and beliefs about poverty, linguistic diversity, immigration, and colonization, among other topics. As a result of the new-found information, I actively sought answers to my questions about social justice, systemic oppression, structural racism, white privilege, positionality and intersectionality, diversity, and equity and inclusion, among other topics and lived experiences. Midway through my doctoral program, I began to realize how woefully inadequate my understanding of diversity, identity, equality, and equity truly was, and I put in the effort to listen, learn, and change. As I continued to educate myself on social justice issues, political policy, and systemic racism, I also began educating myself about the literal interpretations of the 
Bible, the historical and scientific accuracy of the Bible, the beliefs of the early church, and progressive Christian interpretations of the Bible. I went through what ex-evangelical and ex-Christians call "deconstruction." Deconstruction is not a destruction of beliefs but a tearing down of beliefs to reassemble them into something new. ${ }^{4}$ In my case, my deconstruction from Republicanism caused me to deconstruct from evangelicalism and Christianity, more broadly. Without Republicanism, my evangelical, literal reading of the Bible no longer made sense. In truth, my worldview and identity were unraveling one day at a time, and I felt helpless to stop it.

Deconstructing politically and religiously was incredibly painful-too painful to write about here. I felt absolutely unmoored. I became depressed. I woke up crying and went to bed crying almost every day for a year. My physical and mental health suffered, and I sought out therapy. Rather than drifting aimlessly in my spiritual and political confusion, I sought out anchors, such as theory, research, and pedagogy, that would stabilize me. Two of these anchors were developing curriculum and pedagogy committed to exploring diversity and identity in the composition classroom. I hoped by focusing on what I knew-teaching and research-I would find my new, reassembled self.

\section{THE WHY AND HOW: STORYTELLING AND LISTENING TO TEACH DIVERSITY}

\section{The Why: HOUWS and Course Design}

UW-Stout, about sixty miles east of the Twin Cities, is a teaching-intensive institution drawing middle-class and working-class students from mostly rural regions of Wisconsin or Minnesota. Students are attracted to the close proximity of campus to their home communities, usually within a few hours' drive, as well as the smaller campus (ten thousand students) in Menomonie (population sixteen thousand). Local industries are predominantly small- and large-scale farms, technology, factories, and manufacturing, such as $3 \mathrm{M}$, Walmart distribution centers, Anderson Windows and Doors, and Conagra Brands. $86 \%$ of students are white, $2 \%$ are African American, and less than $1 \%$ of students are Hispanic/Latinx or American Indian. In fall of $2016,3 \%$ of students were international, but that number has declined by $50 \%$ (University of Wisconsin-Stout).

For the first two years, I observed campus culture and came to realize there needed to be more conversations with my students about the diversity of everyday experiences. The prejudice and racism on campus and in Menomonie, such as Halloween blackface incidents, community forums to discuss racial bias, and noose images (see Lyon, "Forum," "Stout"; "On-Campus Racial Hate"; Stetzer; "UW-Stout Students Upset"), were annual topics of discussion. As I came to recognize, the campus and community culture frequently stifled meaningful conversations about diversity, equity, and inclusion despite the hunger for these conversations among many faculty, citizens, and students. It is within this context I created and taught the HOUWS curriculum.

Given my own journey from evangelical Republican to deconstructed Christian liberal, I felt extremely underprepared and intimidated to teach the importance of diversity. Like many graduate students and faculty, I was not trained to develop curriculum on identity, diversity, equity, inclusion, or social justice and was not trained in how to create a classroom community that welcomed such conversations (see Gurin, Nagda, and Zúñiga). I was afraid of getting it wrong and saying the wrong thing; I was afraid of creating classroom-management issues (see Hurlbert; Sheets). I was also afraid of negatively affecting my students' learning, especially my working-class students, who often struggled in academia (see Carter and Thelin). Furthermore, I knew my conservative student audience well, including the conservative rhetoric about diversity, social justice, and identity. ${ }^{5}$ In the summer of 2015 , I landed on an approach to teaching diversity that made sense to me pedagogically: I came up with the phrase "the diversity of everyday experiences" to frame diversity, including racial and ethnic diversity as well as diversity of thought and experience, not as a liberal or progressive talking point but as integral to understanding the human experience. I also chose the language of "the diversity of everyday experiences" as an accessible way to talk about the lived experiences of people who were not white, cisgender, and/ or heterosexual.

Because people's stories were so impactful to me in my own growth, particularly through venues including the Native America Calling radio show, the This American Life radio show, Brandon Stanton's HONY, and Minnesota Public Radio, I decided to approach my first-year composition curriculum with a semester-long focus on listening to campus community members' stories to introduce students to the diversity of everyday experiences. I designed the semester around the HOUWS assignment, which came first, and in subsequent assignments students wrote a profile of three HOUWS stories and corresponding photographs, wrote a rhetorical analysis of the HOUWS Facebook site itself, and finished the semester with a portfolio of revised work and a culminating reflection. I also hoped this semester-long focus on HOUWS would create a crack in the veneer of homogeneity that seemed to pervade UW-Stout: I wanted my students to see that not everyone was the same-with similar life experiences, similar beliefs, similar identities, and so forth-to encourage students to lift up the voices of others and to name their own diverse experiences. Taking stories public, through HOUWS and other similar assignments, validates and destigmatizes people's lived experiences. It also creates venues for more open, diverse conversations that might have previously been silenced or relegated to pockets of students or faculty. Dario Gamboni writes, "One way of "making things public" is to make them appear publicly, to represent them in public" (162; italics in original). Similarly, Robert Coles explains, "[A]s active listeners we give shape to what we hear" (19). Publicly representing the lived experiences of campus community members can also 
create a chain reaction in which other people feel comfortable to claim and name their own lived experiences.

\section{The How: The First Six Weeks}

We spent the first six weeks of the semester on the HOUWS assignment. I placed the HOUWS assignment first for four reasons: first, I knew my first-semester students would be naturally curious about their new campus, and an assignment like this one would capitalize upon their curiosity. Second, first-semester students often feel like outsiders, and the assignment gave them the opportunity to assume some leadership and agency, which are vital to middle-class and working-class college students' persistence and retention (see Ballantyne; Collier and Morgan; Mitra). Third, I wanted students to practice actively listening as a means for developing understanding and empathy, which would serve them well as students and as citizens (Ratcliffe 19; see Frey). Finally, as a first assignment, HOUWS would help my students make friends and develop a sense of belonging, both for both student empowerment and academic success (Stephens, Brannon, Markus, and Nelson 3).

In the first two weeks, we listened to This American Life's "Harper High School-Part 1" and "Harper High School-Part 2" in class, which tell the story of Black students growing up in the south side of Chicago and their efforts to navigate family, work, dating, and school while living in the midst of gang violence. I chose the Harper High School series for several reasons. First, my students were recent high school graduates. Second, UW-Stout is a five-hour drive to Chicago, and students are familiar with the local and national rhetoric about the south side of Chicago. Third, I wanted to highlight how This American Life uses storytelling to confront pervasive, sweeping, false narratives about gangs, gang membership, and gang violence. I played twenty to thirty minutes of each episode over the course of two weeks, and while we listened to the episodes, I asked students to take notes of similarities, large or small, they shared with the students being interviewed. At the end of each segment, I asked students to share what similarities they wrote down. Similarities included being on the football team, living in a single-parent household, and a friend dying due to an accidental gunshot wound. The rest of the class period included students researching the history of Harper High School, discussing the importance of telling and listening to the stories of Harper High School students, analyzing the rhetorical situation of the series, and tracking local and national news stories about the south side of Chicago.

The narrative is a powerful genre for confronting the single story because narrative "emphasizes the active, self-shaping quality of human thought, the power of stories to create and refashion personal identity" (Hinchman and Hinchman xiv). Towards the end of week 2, I introduced students to Stanton's HONY Facebook page and Web site. To see how active, self-shaping of identity happens in real time, I had students immerse themselves in the HONY page and Web site. Students read the stories that were interesting to them, and we talked about what they were learning about how the participants shaped their experiences and identities. We also watched behind-the-scenes interviews with Stanton, such as Mashable's YouTube video "This Is the Human behind 'Humans of New York,"' to better understand Stanton's process, experiences, advocacy, and rhetorical purpose.

In week 3, I showed Chimamanda Ngozi Adichie's TED Talk "The Danger of the Single Story" to frame the This American Life episodes within the context of challenging the single stories about Harper High School students and the south side of Chicago. Adichie defines "the danger of the single story" as "show[ing] a people as one thing, as only one thing, over and over again, and that is what they become.... The consequence of the single story is this: It robs people of dignity. It makes our recognition of our equal humanity difficult. It emphasizes how we are different rather than how we are similar" $(9: 22 ; 13: 41)$. I wanted students to understand how single stories-about the south side of Chicago, about Menomonie, or about themselves-falsely define people and places in harmful, reductive ways. By the end of week 3 , I wanted my students to understand storytelling helps people "understand what they ha[ve] experienced by getting them to tell their stories" (Coles 19) and "reaffirm[s] the plurality of stories that different cultures and subcultures may tell about themselves" (Hinchman and Hinchman xiv).

For the last twenty minutes of class at the end of week 3 , I partnered students and sent them out to practice getting their first story and photograph of a HOUWS. Before students left the classroom, I gave them instructions to use Stanton's consent process: (1) first, tell people about the HOUWS Facebook page and see if they are willing to share a story, (2) ask the participants how much of their face they want visible on Facebook before taking the photograph, and (3) if at any time participants wanted their stories and pictures removed from Facebook, they could e-mail me through my university e-mail address, which was listed on the Facebook page. Then off they went. Twenty minutes later, students returned buzzing with energy and fascinated by the openness of complete strangers. One group spoke with department staff celebrating the birthday of a colleague; another group talked with a vice provost eating lunch; another group spoke with a janitor cleaning a bathroom; other groups spoke with students waiting for classes to begin. In all cases, my students were gleefully surprised that strangers would be willing to share their stories with them. The class period ended with student energy at an all-time high.

In weeks 4 through 6, students, either individually or in pairs, collected six stories and corresponding photographs of campus community members and uploaded them to the Facebook page. In almost every class period, I devoted the first ten minutes of class to talk with students about the people they were meeting, to discuss challenges that arose, and to foster community and learning by giving students time to read the stories their peers 
had uploaded. At the end of week 6, students submitted their final HOUWS story and wrote an out-of-class reflection (Appendix B).

The following three HOUWS stories, accompanying student reflections, and class process work, confirm, as James points out, HOUWS is not simply a "pointless assignment" but creates a transformative experience for students to learn about the diversity of everyday experiences.

\section{CELEBRATING THE HUMANS OF UW-STOUT IN ENGLISH 101}

\section{Sara and Clarissa: Telling Stories to Create Community}

Sara and Clarissa, two white students who teamed up to complete this assignment, collected stories and photographs that reveal a clear rhetorical purpose: to build community among UW-Stout students. Sara and Clarissa were already familiar with HONY and were very excited-and felt a huge sense of responsibility-to mirror Stanton's rhetorical purpose in their HOUWS stories and photographs. As I learned after the fact, they met this student early in the semester and were so moved by their story they wanted to share it to give other students on campus hope (see fig. 1).
Sara and Clarissa wanted to change the lives of those reading our Facebook page by creating a sense of community among readers. In particular, they wanted readers to know of the importance of supporting and accepting each other, especially in difficult times. As Sara writes in her reflection, she wanted to develop "a sense of community" through her posts because "people need people." Sara writes,

I know from personal experience that when things are difficult it is so helpful when there are other people that had similar experiences. It is for those reasons I shared my friend's coming out story. I want people to feel less alone. I also shared some stories because I wanted the readers to know there's more than meets the eye. I would like people to be more aware that what we see every day from people is just a scratch on the surface, people are incredibly and undeniably complex. You can't tell from a first encounter exactly what kind of things a person has experience.

\section{Similarly, Clarissa writes in her reflection,}

My goal for this project was originally to just do what I had to do so I could get a good grade, but after the practice run, I realized that there's a lot of people at Stout with interesting stories to tell. Then my main focus shifted to wanting to share people's stories. I wanted to be able to give Facebook

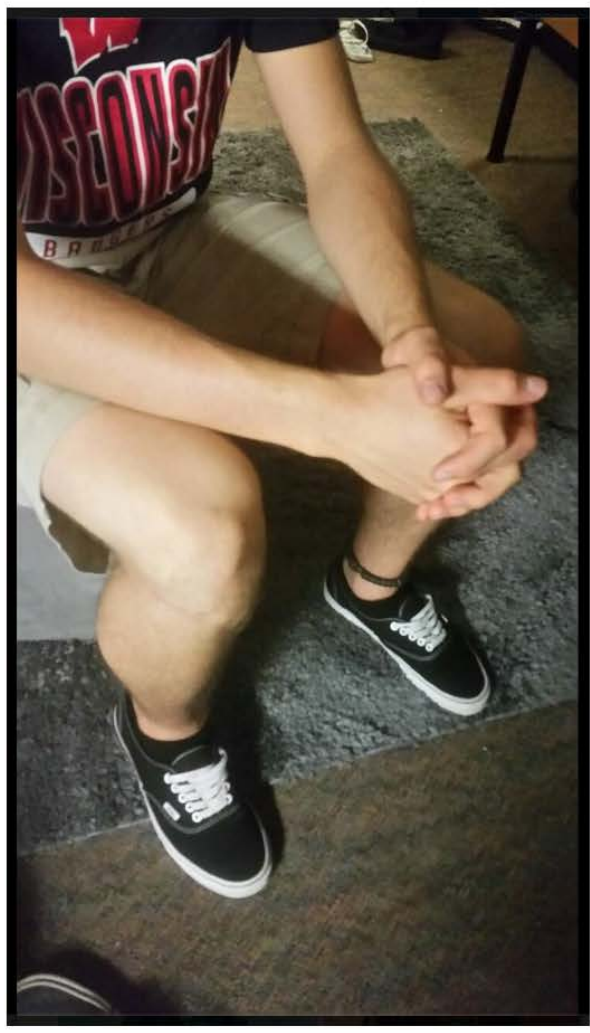

"When I came out to my parents I left a letter on their bed before I left for school. I was super nervous all day. My mom picked me up from school that day and she didn't talk at all, the entire ride home was silent. That night my parents confronted me and basically told me it wasn't real. They ostracized me and I just instead started going into myself and not really having anything to do with any people. I would try to have conversations with them and try to bring up normal conversations and they didn't want to talk about anything so I just finally stopped talking to them after a while. Every day when I would come home from school I would just go outside and walk around and cry and cry and cry for like two hours. After my 17th birthday I started getting depressed and I wouldn't talk to anybody at school and my grades started slipping and my parents started yelling at me, which was the only thing they would talk about and I lost a friend because she moved away. She was the main support I had and without her I felt even more lonely. Then I hit rock bottom, I couldn't do anything and I didn't want to go to school and I was absolutely emotionally unstable and so one night I thought that I would just kill myself. I saw a bottle with a bunch of painkillers in the medicine cabinet and I got them down and went to my room and my friend started texting me frantically and she said if I stopped texting her she was going to call the police and tell them that something had happened to me. So I guess in that way she saved me. When I got to school she made me talk to her about it and talk to a counselor about it and after that things started getting better. Four months after I came out my parents started talking to me again, they started realizing I was miserable. They actually didn't know I was going to commit suicide. They actually still don't know. We never really talked about me being gay. Even to this day they still think it's a phase, it doesn't exist to them."

Figure 1. Sara and Clarissa's Story 
readers and who ever visit the Humans of UW-Stout page an insight into people lives. I want readers to be able to possibly connect with the individual stories that they read. One girl that Sara and I interview talked about losing her grandma who was really close to her. Other people who have loss someone close could read her story and feel connected. We also had stories about going through hardships as a way to let other people know they aren't alone. We also wanted to share stories about good things that are going on in someone's life to possibly lift someone else's spirit.

Throughout the HOUWS assignment, Sara and Clarissa's stories focused on developing community support and the need for connection while highlighting the diverse lived experiences of UW-Stout students. Krista Ratcliffe writes, "[W]e also have to listen to other people, not so that they will do the work for us but, as Morrison reminds us in Beloved, so that we and they may lay our stories alongside one another's" (8; italics in original). Sara and Clarissa wanted readers to lay their painful stories alongside the story of this student coming out to their family to carry the shared load of the pain but also to be reminded that the Facebook page readers and those who bravely share their stories, like this student, are not alone. Also, Sara and Clarissa's posts shake up the assumptions students make about each other. On a campus where many of my students told me they felt compelled to fit in, not make waves, and not ask questions, it was important to many of my students to acknowledge each other's lived experiences.

I want to pause for a second and focus on Sara and Clarissa's approach to sharing their stories because it was very different from the majority of my English 101 students. Sara and Clarissa sought to tell very detailed stories closely modeled on Stanton's storytelling style. While most of my first-year students truncated their stories because, as one student told me in class, they "don't like reading long posts online," Sara and Clarissa shared in class they wanted to model their level of detail on Stanton's HONY stories because they found detailed stories more compelling than shorter ones. Even though I did teach about the importance of telling a story-and how description and detail were important to creating reader engagement-Sara and Clarissa had a sophisticated and mature understanding of the rhetorical and emotional power of detailed stories to elicit readers' action, empathy, and compassion. They seemed to already understand that "people who read longer networked narratives [on Facebook] were more likely to be narratively engaged, thus, they were more likely to share the post" (Wang, Kim, Xiao, and Jung 153). This is just one example of how FYC students take ownership of an assignment by internalizing the responsibilities and making decisions to match their vision.

\section{Claire and Joleen: Design Choices for Greatest Audience Impact}

Claire and Joleen, another team of two white students, took a different approach than Sara and Clarissa: they stylized their photographs and truncated their stories for the greatest possible impact for their intended audience, college students (see fig. 2).

"I was in an abusive relationship for four years. What I thought was his way
of showing me love was actually abuse."

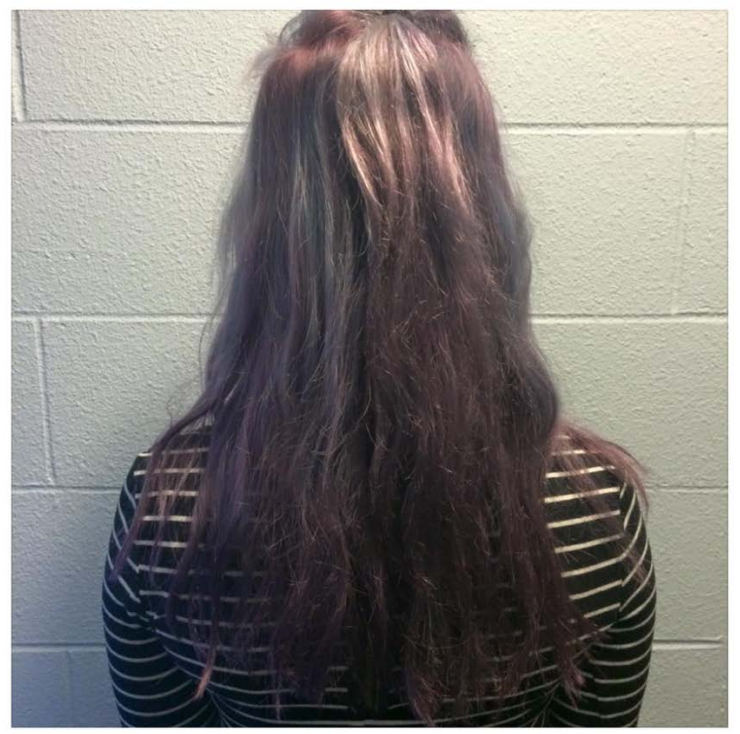

Figure 2. Claire and Joleen's Story

As we talked about this specific post in our class discussion, Claire and Joleen explained they spent about an hour talking with this student, but they chose to pick the most salient quote to capture the crux of this student's experience. Furthermore, they chose to stylize the student in the photograph: they asked her to turn her back to the camera because they wanted to capture the facelessness of this student to visually represent how she felt in her abusive relationship. They also asked her to stand against a concrete interior wall to evoke feelings of "impassability" and "confinement," which were feelings the student experienced while in her abusive relationship. Even though I originally asked students to not truncate stories or overly stylize photographs, Claire and Joleen seized their rhetorical agency as audience-aware content creators who understood the discourse moves necessary to capture their audience's attention (Gee 4).

Claire and Joleen did not write about this student's story in their reflections, but they did write about their own rhetorical purposes, which clearly informed their decisions. Claire writes,

I wanted something raw, something interesting, but to get it the person must truly be willing. What I did find not only was exactly what I feared, but also the complete opposite. I found that no matter how comfortable I tried to make some feel they simply didn't like the fact that others would be able to know the story correlated to them, or simply just weren't comfortable sharing something deep. So they would give me small things, things I still enjoyed posting, but nothing close 
to the depth I was hoping to get. Yet, on the opposite side I found those that were willing to share their stories, truly wanted others to hear them.

Joleen, a self-described introvert who rarely spoke in class, was very nervous about this assignment. She wrote in her reflection it was "kind of scary" to walk up to strangers and say "hi." But the more she "put herself out there," the easier it got to meet and talk with people. Even though Joleen was nervous about this assignment, she appreciated the opportunity to meet different people and listen to their stories. She writes,

When other students and staff read our stories I would like them to think that they are not alone in what they believe in or what they think. I also think that it would be awesome to see new friendships start because of these posts. All of the stories that Claire and I posted were of people that I didn't know, and some of them had pretty cool stories. For example, one girl that we talked to came from a big family with many brothers and sisters. She fluently speaks four languages and she says that learning new languages comes pretty easy to her. She was very nice and open to talking to us as well. I am glad that I had the chance to talk to all of them because it gave me the opportunity to meet a few new people on campus.

This partnership was not smooth sailing for Claire and Joleen, however. Claire and Joleen had different approaches to this assignment, which created a bit of tension. Claire wanted to tell raw stories for a very specific audience, and Joleen seemed to be more interested in meeting fellow students, perhaps to help her feel more comfortable and connected to those around her. Towards the end, Claire started collecting photographs on her own, which hurt Joleen's feelings.

Claire was so invested in this assignment she became frustrated with how her classmates were approaching the assignment. Unprompted by me, she writes in her reflection,

Though one thing that I found a bit irritating or frustrating was the fact that some kids posted the most ridiculous things. Maybe it's the fact that we are on different maturity levels, or possibly it may be that I took the assignment a bit too seriously. Now don't get me wrong, I feel everyone should be given the same chance to post what they felt was their story, but for a few of them I found myself thinking why the heck would someone post this. Maybe they were trying to be funny, or get a rise out of the audience, but I do feel the students should have done a better job on picking picture and quotes that represented our overall goal of the page.

I understood where Claire was coming from. I admit some of the stories and photographs made me wonder if students truly understood the purpose of the assignment-or if the assignment took them too far out of their comfort zones and would be better suited for an upper-division class-but then I decided to shift my perspective away from worrying I somehow failed at my curriculum design to believing each story and photograph represented what each student understood about the diversity of everyday experiences. Some of those interpretations focused on sports, career choices, missing home, video games, tragedy, and tattoos. If anything, this assignment taught me students' interpretations of the diversity of everyday experiences would be ... diverse.

\section{Joe: Telling Black Student Stories to a White Campus}

Even though I have focused this essay on what I wanted to teach my white students about the diversity of lived experiences, I want to share the story and reflection from Joe, a football player and the only Black student in my English 101 section, to draw attention to the double-consciousness Black students experience on a daily basis on a predominately white campus. W. E. B. Du Bois calls "double-consciousness" a consciousness that makes Black Americans explicitly aware of their "two souls, two thoughts, two unreconciled strivings, two warring ideals" within white America (5).

In class Joe told me he wanted to tell the stories of Black students and how their experiences differ from white students. He explained many Black student athletes were coming to UW-Stout from the Chicagoland area and were facing various challenges with the adjustment-but there were positive experiences as well that should be shared (see fig. 3). In this story, Joe shares with the HOUWS readers how some Black students' dating and friendship experiences might be very different from white students' experiences.

"Back home I didn't mess with white girls, but Stout has changed me for the better."

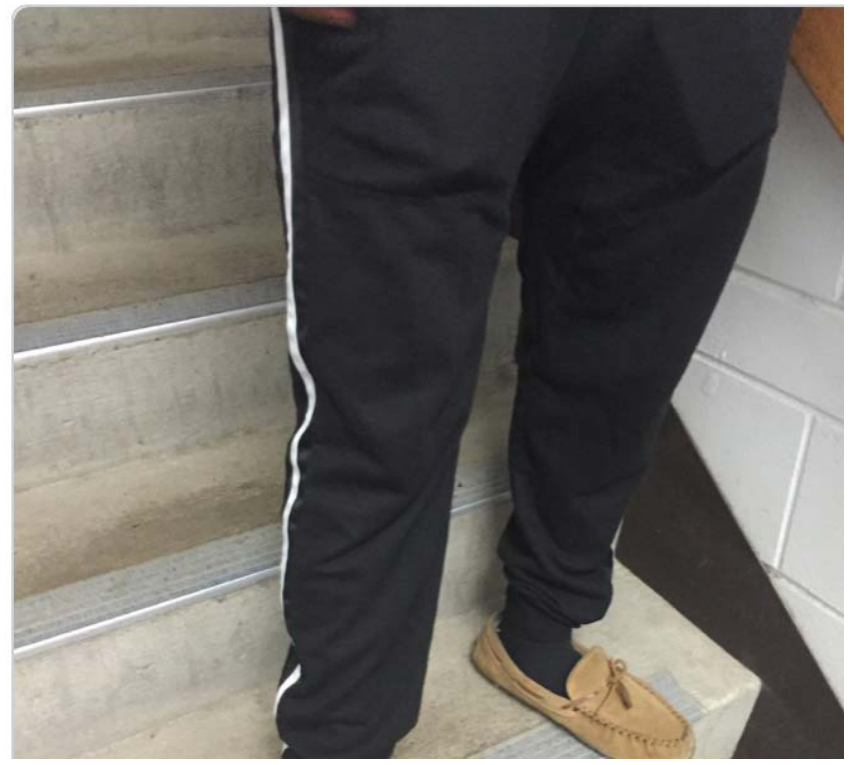

Figure 3. Joe's Story 
During a small group discussion, I asked Joe what he meant by "mess with." I was not sure if it meant dating white girls, talking to white girls, or developing friendships with white girls. Joe explained this athlete went to a high school with very few white students, and he never dated or became friends with white girls in high school. Being at UW-Stout gave him the opportunity to interact and get to know white students in a way he had not had the opportunity to previously. When Joe shared this story with a predominately white campus audience, he named the double-consciousness Black students experience as a part of everyday life. He also named the segregated schooling and segregated friendships many students of color still experience. Michael Awkward explains Black Americans' "attempt to resolve double-consciousness" by being "initiated into the larger American society ... to seek both the origin and an understanding of the often self-aggrandizing myths of the "more prestigious group"' (67). They "must seek to understand the origins of myths, "how things came to be what they are"" (67). Dating white students might be one way Black students seek to understand and resolve double-consciousness. Interracial relationships, sociologist René D. Flores explains, "are a form of boundary crossing" and "uncover the existence of interaction across group boundaries and also signal that members of different groups accept each other as social equals" (271). Moreover, it is possible some Black students attend regional universities like UW-Stout for the affordable education but also to attempt to resolve their own double-consciousness and/or to learn how to navigate white America.

Dispelling the single story of lived experience was very important to Joe. In his short reflection, he writes,

There are to many single stories about individuals, I hope that this will help the followers gain a different perspective and with that not be so quick to judge. If the followers don't relate to any of the post and can't find anything to take away from them, I hope that they can find happiness in the post or at least get a break during their day to visit the page and view the new post.

Joe's purpose, much like the rest of my students, was to teach readers about the diversity of everyday experiences and to combat assumptions and judgment. While I want to be careful about making assumptions about his purpose and whether or not he saw HOUWS as an opportunity to dispel the single stories about Black students, it may not be a stretch to assume Joe saw the HOUWS page as an opportunity at a "counter-space" to "establish a positive racial climate" and "provide informal safe havens" for students of color within a campus and community that struggled with the hard work of examining white privilege and white fragility (Jackson and Hui 464).

\section{IN THEIR OWN WORDS: MY STUDENTS' EXPERIENCE WITH THE HOUWS ASSIGNMENT}

Because this was a new assignment, I wanted to gather as much information as possible about what students learned from it. Almost every class period included a metacognitive exercise or direct questions about what students were learning. Overall, students did not naturally write about diversity, the diversity of everyday experiences, or the danger of the single story unless they were specifically prompted. Rather, students wrote about the importance of not judging others based on what they look like, not making assumptions about a person's experiences, the importance of listening, and the challenges of being a college student. In the following section I share the voices of my other students to highlight their learning in their own words.

\section{Are the Stories Going to Make a Difference?}

In week 4, I asked students in a homework discussion thread post, "Do you think that the Humans of UW-Stout stories might help people feel more connected on campus? Why or why not?" and "What are our obligations as storytellers, knowing that people can get something —or nothing-out of the stories we share?" Tim responded, "Yes, I do think that the Humans of UW-Stout stories will help people feel more connected on campus because they will be able to relate to people they never thought they would." In answering the second question, he writes, "To not be biased and share stories as they are told. The way people are able to feel of the person sharing and feel more connected to them." McKenzie writes, "Yes, it gives you a chance to get to know the people that you may pass by on the sidewalk or even in your classes without being able to make any prior judgments" and "the presentation of the story is more important than the story itself. our lives are made up of stories that usually arent interesting or entertaining but theyre what makes up [us] unique and different." And Melanie writes, "Yes, I think this page will give insight to the students that we all do more than just homework, go to class and eat food. This page will show that we are individuals and enjoy different things." To the second prompt she adds, "I believe our duty is to tell raw stories. We should be real, we shouldn't filter the stories. If a student does tell you their life story choose to share the parts that you believe are the most impactful." Overall, students agreed the page would be impactful, particularly to help other students find friends with common interests, to teach students not to judge each other, and to show college student life is more than parties and homework.

\section{Does Listening Matter?}

In a week 5 homework discussion thread post, I asked students, "What do you need to practice in your own listening skills of ways that you listen?" Most students responded they need to do a better job actively listening and agreed it was beneficial to listen to others. Chelsea writes, "I need to learn to ask more questions about others around me to get to know them better." Julia writes, "One phrase l'm trying to live by is 'Listen to others, don't just wait for your turn to speak.' I know that I need to pay more attention to 
other people, especially people that annoy me sometimes." In that same homework post, I asked students to respond to whether or not they agreed "listening to others' might make us better people." Ryan writes, "Yes, I think it is true that we gain certain things from listening to other people such as patience and knowledge." Erik admits in his post, "I can be very stubborn when it comes to views that are different then mine, I will do less listening because in my mind I know i'm right." And Jeremy explains, "Yes, it makes us a better person in the aspect of allowing us to gather information and also it lets other people feel that they are welcome." Whether students are open to listening to others who are not like them, I do not know. But I do hope that by impressing upon students the importance of active listening they will be more inclined to listen to all sorts of people.

\section{What's the Importance of the Danger of the Single Story?}

In weeks 4 and 5 , I returned students to reflecting upon and writing about the danger of the single story. I was not sure if they were making the connection between HOUWS and how HOUWS can dispel single stories through their own acts of storytelling. In responding to my week 4 prompt about Adichie's rhetorical purpose, all students understood her rhetorical purpose. Billy writes, "She is trying to tell you that people are more than one thing. There are different people, that live their lives differently in every culture." Similarly, Mike writes, "She is telling people that all people are victims of telling and hearing a single story and it could cause a negitive effect on people." In week 5, I wanted to see what students were internalizing about the danger of the single story. I asked in a homework assignment, "What are the dangers of a single story?" Billy writes, "It categorizes everyone into a single person. Doesn't make anyone orignal." Mike writes, "That they create stereotypes that are not bad for being untrue but they are also not the full truth." While Billy and Mike are not wrong, they do not fully understand or are not sure how to articulate Adichie's point. Nick does, though: "It makes room for biases and it makes you much more close-minded and blind to the world." And Mary does: "Single stories form stereotypes and allows people to make assumptions on things they are not too familiar with." All of my students' responses were one sentence except Kelly's:

The dangers of a single story are many. One is that someone assigns a face value to a person, place, or thing without assessing other facors. Stereotypes and misaligned perceptions come into play when judging a book by it's cover. Single stories hold us back as a culture. Opening ourselves up to new perspectives allows us to foster creativity and growth.

Beyond students' reflections, which were sometimes vague, I do not have as many meaty and satisfying answers as I would like from students about their growth or experiences with this assignment. The majority of students' responses to homework and reflection questions were one sentence. This was a pretty consistent trend I saw across my FYC sections. I do not know if students did not think they needed to write more, if they did not have something to say, if this was an indication of their unfamiliarity with academic expectations, if it was a sign of my failing to teach students to explain and develop their ideas, if it was the midwestern politeness, or what the reasons might have been.

\section{CONCLUSION: LOOKING BACK AND LOOKING FORWARD}

When I reflect on this assignment and who I was at the time, it is clear my own apprehensions and fears impacted my teaching of the curriculum. Because of my apprehensions and fears, I made assumptions about students' beliefs and experiences-and developed curriculum based on those assumptions-simply because I did not know how to ask them about their beliefs, experiences, and identities. If I were to teach this assignment again, I would do a pretest at the beginning of the unit and a posttest at the end to better gauge students' understanding of diversity and the danger of the single story. I would ask them more direct questions, such as,

- How do you define diversity?

- How does diversity show up in your own life?

- Do you believe diversity is important? Why or why not?

-What single stories do you believe?

-Where do you see single stories happening on campus?

-What single stories can you help dispel?

-What are your identities?

- How do your identities shape your understanding or perspective of the world?

- How do your identities shape your daily life?

I would also dive into diversity and intergroup relations curricula, such as the curriculum available through the University of Michigan's Program on Intergroup Relations (which I received training in), particularly curriculum teaching white students to examine and reflect upon (1) their identities, (2) how their identities shape how they see and experience life, and (3) how the identities of students of color shape how they see and experience life. I truly wish I had been taught, as a teenager and young adult, to reflect on my own identities beyond evangelical Christianity and Republicanism. Having gone through my own identity deconstruction, I see how important it is to teach white students about their own complex, nuanced identities beyond the single story they might believe about themselves-from Wisconsin, a hockey player, a Christian, a math major, and so forth. We often tell single stories about ourselves, just as I did, and I want my students to know they are more than one or two stories.

The Humans of UW-Stout Facebook page has over five hundred stories. And those stories unequivocally capture the diversity of everyday experiences: the experiences of ROTC students, international students, resident advisors, department staff, athletes, custodians, student employees, classmates, and friends. More than anything, the stories capture university life in a way that 
helps students feel they belong, they matter, and they are not alone. And each of my English 101 students took ownership of this assignment and made it meaningful for themselves in some way. Honestly, in spite of my self-critiques, I am so proud of my FYC students and the stories they told. My students were curious changemakers and conduits. One human at a time.

\section{Notes}

1 I chose to create a mash-up genre because the traditional research essay is too formal for the story I want to tell, and a personal essay does not allow for the classroom research I want to share with Writers: Craft \& Context readers. Therefore, a blend of both the personal essay and the traditional research essay allows me the flexibility to coherently incorporate my personal journey and my research findings.

2 All data collected has been IRB-approved. Students' names are pseudonyms, their writing style is unedited, and reflections are excerpted

3 For those interested in reading more about Christian evangelical identity construction, faith, and politics, I recommend Lydia Bean's The Politics of Evangelical Identity: Local Churches and Partisan Divides in the United States and Canada and Sally K. Gallagher's Evangelical Identity and Gendered Family Life.

4 In many former-conservative and evangelical circles, people talk about themselves as "deconstructed evangelicals" or "deconstructed Christians" as a way to define their current stage of assemblage: they are trying to make sense of what they used to believe while also trying to figure out what to throw away and what to keep, if anything at all. In all cases I have seen online and elsewhere, "deconstruction" always means a leaving behind of political or religious conservatism for more inclusive, spiritual, agnostic, and/or progressive beliefs. To read more about Christian deconstruction, I recommend Gerardo Marti and Gladys Ganiel's The Deconstructed Church: Understanding Emerging Christianity.

5 This is one example of such rhetoric: Michelle Malkin's 'Readin', Writin', and Social-Justice Agitatin'.." 


\section{APPENDIX A}

\section{HUMANS OF THE UNIVERSITY OF WISCONSIN- STOUT ASSIGNMENT PROMPT}

For this assignment, you can work alone or with a partner.

Using the Humans of New York Facebook page as inspiration, you will venture out into the UW-Stout community and become an amateur street photographer. You will upload peoples' pictures and stories to the Humans of UW-Stout Facebook page.

\section{Assignment Task}

You are asked to find six people, couples, or families whom you do not know and who are willing to allow you to take their picture and ask them a few questions. The objective is to share people's stories, to make their voices heard, and to challenge the single story. It is also meant to get you connected to the Stout community and to become a contributing member of that community. People want to be heard, and people want to know they aren't alone.

\section{Guidelines for Stories}

When approaching a stranger, you might want to open like this: "I'm working on a class project called 'Humans of UW-Stout' and I am collecting people's stories to share on Facebook. Would you mind if I told your story?" I also recommend you giving them your (or my) email address, so that if they want to change their mind later, they can email you. Remember: we want happy participants!

The stories don't need to always be serious or deep. But what you want to get are real parts of people. You can let them say what they want to share, or you might ask these questions:

- "Why are you studying at X?"

- "What is the meaning of life?"

- "When was the saddest moment of your life?"

- "What are you doing?"

- "What is the biggest struggle you face?"

- "If you could give one piece of advice to a large group of people, what would it be?"

When listening to people's stories, either record their responses on your phone, or write their responses down in a notebook. You want to make sure that you are accurately recording their stories. If, at any time, the participant changes their mind, always thank the participant and move on.

When typing out the story on the Facebook page, make sure that you spell check and use correct grammar. This improves our credibility and helps others take our page seriously.

Guidelines for the Photographs
There are no specific guidelines for the photographs, except that they must be original photographs taken by you for purposes of the assignment, and the subject can't be someone you know. You should not "model" the participant, but you can ask that they pose in an interesting way. Emphasize that pictures should be natural and interesting, not overly staged or selfie-like.

You can always offer to keep the participant anonymous, by taking a picture of part of their body, or allowing them to obstruct their face in some way.

\section{Posting Content to the Facebook Page}

When posting content to the Facebook page, you are responsible for uploading the picture and the participant's stories. When you are quoting your participants, make sure to use quotation marks. Your stories can be as short as a sentence or as long as a paragraph. Longer stories do not mean better stories.

\section{APPENDIX B}

\section{HUMANS OF THE UNIVERSITY OF WISCONSIN- STOUT FACEBOOK ASSIGNMENT REFLECTION}

\section{The Task}

In this assignment, you will be reflecting upon the Humans of UW-Stout Facebook project. You will write your reflection in the form of a memorandum, and l've included instructions for what you should write about in each paragraph.

\section{Reflection Memo, 1+ pages, single-spaced, Times New Roman, 12 point font, 1" margins}

Follow the memorandum example uploaded to the course management site. Your memo should include, in this order:

Section 1. A two-to-three sentence purpose statement in which you summarize the purpose of the memo (your reflection on the assignment to me, Dr. X).

Section 2. In one paragraph, tell me what you hope Facebook readers and Humans of UW-Stout followers gain from your pictures and stories. Describe your purpose(s) for sharing the stories and pictures that you did and the effect(s) you want your stories and pictures to have on the readers.

Section 3. In one paragraph, compare your biggest fear or challenge to what actually happened: Did your fears or challenges come true? Or were you pleasantly surprised about your experiences?

Section 4. In one paragraph explain what have you learned from this project. You can write about what you've learned about yourself 
or what you've learned about others. You might want to focus on if you feel like you're more connected to the Stout community.

Section 5. In one paragraph reflect upon the three most impactful readings that we read and discussed. Write about how you were impacted by the readings and if they impacted how you approach storytelling, others' stories, the people you encounter, or your approach to the Facebook project. You will need to format your citations or paraphrase in APA formatting.

Section 6. Tell me anything else related to this assignment. You might want to focus on what was difficult, or about a problem that arose, what you really liked-anything you think I should know and/or like to read about.

Section 7. A brief conclusion in which you summarize your important points. Thank the reader and include your email and phone number.

\section{Works Cited}

Awkward, Michael. Inspiriting Influences: Tradition, Revision, and Afro-American Women's Novels. Columbia UP, 1989.

Adichie, Chimamanda Ngozi. "The Danger of a Single Story." TEDGlobal, 2009, https://www.ted.com/talks/ chimamanda_ngozi_adichie_the_danger_of_a_single_ story/transcript?language $=e$.

Ballantyne, Julie. "Valuing Students' Voices: Experiences of First Year Students at a New Campus." International Journal of Pedagogies and Learning, vol. 7, no. 1, 2012, pp. 41-50.

Bean, Lydia. The Politics of Evangelical Identity: Local Churches and Partisan Divides in the United States and Canada. Princeton UP, 2014.

Carter, Genesea M., and William H. Thelin, editors. Class in the Composition Classroom: Pedagogy and the Working Class. Utah State UP, 2017.

Coles, Robert. The Call of Stories: Teaching and the Moral Imagination. Peter Davidson, 1989.

Collier, Peter J., and David L. Morgan. "Is That Paper Really Due Today?': Differences in First-Generation and Traditional College Students' Understandings of Faculty Expectations." Higher Education, vol. 55, 2008, pp. 425446.

Du Bois, W. E. B. The Souls of Black Folk. Millennium, 2014.

Duyvendak, Jan Willem, Nancy Foner, and Philip Kasinitz. Super-Diversity in Everyday Life. Taylor and Francis, 2020.

Flores, René D. "'A Little More Ghetto, a Little Less Cultured': Are There Racial Stereotypes about Interracial Daters in the United States?" Sociology of Race and Ethnicity, vol. 6, no. 2, 2020, pp. 269-286.
Frey, Renea. "Rhetorics of Reflection: Revisiting Listening Rhetoric through Mindfulness, Empathy, and Nonviolent Communication." JAEPL: The Journal of the Assembly for Expanded Perspectives on Learning, vol. 23, 2017-2018, pp. 92-104.

Gallagher, Sally K. Evangelical Identity and Gendered Family Life. Rutgers UP, 2003.

Gamboni, Dario. "Composing the Body Politic: Composite Images and Political Representation, 1651-2004." Making Things Public: Atmospheres of Democracy, edited by Bruno Latour and Peter Weibel, MIT P, 2005, pp. 162-195.

Gee, James Paul. Social Linguistics and Literacies: Ideologies in Discourses. Routledge, 2015.

Gurin, Patricia, Biren (Ratnesh) A. Nagda, and Ximena Zúñiga. Dialogue Across Difference: Practice, Theory, and Research on Intergroup Dialogue. Russell Sage Foundation, 2013.

"Harper High School-Part One." This American Life. Nat. Public Radio, 2 Feb., 2013. https://www.thisamericanlife.org/487/ harper-high-school-part-one.

"Harper High School-Part One-Part Two." This American Life. Nat. Public Radio, 15 Feb., 2013, https://www. thisamericanlife.org/488/harper-high-school-part-two. Hinchman, Lewis P., and Sandra Hinchman. Memory, Identity, Community: The Idea of Narrative in the Human Sciences. SUNY P, 1997.

Humans of UW-Stout Facebook Page. https://www.facebook. com/humansofuwstout.

Hurlbert, Claude. National Healing: Race, State, and the Teaching of Composition. Logan: Utah State UP, 2012.

Jackson, Brandon A., and Mary Margaret Hui. "Looking for Brothers: Black Male Bonding at a Predominantly White Institution." The Journal of Negro Education, vol. 86, no. 4, 2017, pp. 463-478.

Lyon, Barbara. "Forum Explores Community Response to Bias Incidents." Chippewa Herald, 9 Dec. 2014, https:// chippewa.com/dunnconnect/news/local/forum-explorescommunity-response-to-bias-incidents/article_276879de9252-5c7a-a05a-9236662256d7.html. Accessed 29 Apr. 2021.

--. "Stout Police Cite Menomonie Man with Hate Crime." Chippewa Herald, 1 Dec. 2014, https://chippewa.com/ dunnconnect/news/local/stout-police-cite-menomonieman-with-hate-crime/article_0f1b1ea9-89f1-5b42-b89d5fb70c33238d.html. Accessed 29 Apr. 2021.

Malkin, Michelle. "Readin', Writin', and Social-Justice Agitatin'.". Washington Examiner, 8 Aug., 2014. https://www. washingtonexaminer.com/readin-writin-and-social-justiceagitatin.

Marti, Gerardo, and Gladys Ganiel. The Deconstructed Church: Understanding Emerging Christianity. Oxford UP, 2014.

Mashable. "This Is the Human Behind "Humans of New York." YouTube, uploaded by Mashable, 15 Oct., 2013, https:// www. youtube.com/watch?v=Bcm6kwWv09o. 
Mitra, Dana L. 2004. "The Significance of Students: Can Increasing 'Student Voice' in Schools Lead to Gains in Youth Development?" Teachers College Record, vol. 106, no. 4, 2004, pp. 651-688.

"On-Campus Racial Hate Leads to Strengthened Resolve." Stoutonia, 3 Dec., 2014. http://stoutonia.com/on-campusracial-hate-leads-to-strengthened-resolve-2/.

Ratcliffe, Krista. Rhetorical Listening: Identification, Gender, Whiteness. Southern Illinois UP, 2005.

Rymes, Betsy. Communicating Beyond Language: Everyday Encounters with Diversity. Taylor and Francis, 2014.

Sheets, Rosa Hernández. Diversity Pedagogy: Examining the Role of Culture in the Teacher-Learning Process. Pearson/ Allyn Bacon, 2005.

Stephens, Nicole M., Tiffany N. Brannon, Hazel Rose Markus, and Jessica E. Nelson. "Feeling at Home in College: Fortifying School-Relevant Selves to Reduce Social Class Disparities in Higher Education." Social Issues and Policy Review, vol. 9, no.1, 2015, pp. 1-24.

Stetzer, Rod. "Sparx Ordered to Pay Employee Fired for Complaint about Racist Drawing." Chippewa Herald, 6 Feb. 2014, https://chippewa.com/dunnconnect/news/local/ sparx-ordered-to-pay-employee-fired-for-complaint-aboutracist-drawing/article_90d9e33d-

University of Wisconsin-Stout Enrollment. 2020. Fact Book. Planning, Assessment, Research \& Quality. https:// public.tableau.com/views/FactBookEnrollmentTest/ Story 1 ?\%3Aembed=y\&\%3AshowVizHome=no.

"UW-Stout Students Upset over Blackface Halloween Costume." FOX6. KMSP. 5 Nov. 2015, https://www.fox9.com/news/ uw-stout-students-upset-over-blackface-halloweencostume.

Wang, Ruoxu, Jingyoung Kim, Anli Xiao, and Yong Ju Jung. "Networked Narratives on Humans of New York: A Content Analysis of Social Media Engagement on Facebook." Computers in Human Behavior, vol. 66, 2017, pp. 149153.

Wise, Amanda, and Selvaraj Velayutham, editors. Everyday Multiculturalism. Palgrave Macmillan, 2009. 